\title{
THE SOFTWARE FOR AN 'UNIVERSAL GRAPEVINE DATABASE'
}

C. D’Onofrio, G. Scalabrelli

Department of Fruit Science and Plant Protection, section of Fruit Science, University of

Pisa, Via del Borghetto 80, 56124 Pisa, Italy

Corresponding author: C. D’Onofrio (c.donofrio@agr.unipi.it)

Keywords: ampelographic-ampelometric-phenological descriptors, grapevine variety, Italian Vitis Database, microsatellite profile, similarity index, standardization

\begin{abstract}
A software for an "universal grapevine database" has been developed to support the activity of characterization of grapevine biodiversity. This database allows a decentralized data management: the registered users have the possibility to submit and to manage his own data at any time. The uploaded data have three different levels of visualisation: private level (the data are visible only to his submitter), middle level (the data are visible to all other submitters), public level (the data are visible to all public users). Only the data approved by a specific scientific committee can be elevated to public level. When a submitter introduces the microsatellite data in the database the application allows a specific standardization procedure based on some specific selected accessions called 'system accessions'. The main classes of data represented in the database are the 'grapevine variety', the 'ampelographic-ampelometric and phenological-productive descriptors' (as reported in the second edition of the OIV descriptor list for grape varieties and Vitis species), the 'microsatellite profile', the polyphenols and aroma profiles. Several search options have been implemented: a search by variety and other general parameter, a search by ampelographic and ampelometric parameters, a search by microsatellite profile. About microsatellite profile it is also possible a search by range and by a particular standardization procedure. The application has been implemented using the most recent database software and languages, so it is flexible and dynamics especially as concern the addition of other classes of data, like new type of descriptors and molecular markers. The application is on the web at http://www.vitisdb.it and at present it is adopted for the 'Italian Vitis Database' managed by the "Vitis Database Working Group".
\end{abstract}

INTRODUCTION

In viticulture the identification of variety is extremely important for commercialization of planting materials, for recovery, characterization and valorization of local germplasm, and therefore for preservation of biodiversity. But, the high number of varieties, their rapid diffusion, their morphological and phenological variability, and consequently the presence of many synonyms and homonyms, get grapevine variety's identification particularly complex.

The development of DNA molecular markers during the last decades, and in particular of 'microsatellite' molecular markers, provides the opportunity, as never before, to identify with certainty each grapevine variety. 
In this contest, the Department of Fruit Science and Plant Protection, University of Pisa, created the application for a 'Universal Grapevine Database' that supports some important innovations.

In 2004, Dr. Claudio D'Onofrio, made the logical and conceptual scheme of an universal grapevine database as his activity of thesis in the master of bioinformatics at the University of Turin (D'Onofrio, 2004). This project was presented during the Italian national symposium on autochthonous grapevine varieties in 2006 ('I vitigni autoctoni minori: aspetti tecnici, normativi e commerciali', 30 November - 1 December 2006, Turin). In February 2007, in a meeting among the members of the majority of the Italian viticulture research Institutions, it was proposed the physical implementation of the above application and the adoption for a possible Italian grapevine database. Thanks to the financial support of the agriculture society 'ColleMassari s.p.a.', it was achieved the physical implementation of the proposed application. The application was presented in a following meeting among the members of the Italian viticulture Institutions in May 2008. The participants of this meeting definitively decided for the adoption to the presented application for the 'Italian Vitis Database' and established the "Vitis Database Working Group" (Fig. 1).

The application was also presented in Gödöllö, Hungary, during the "Second Annual Workshop for the EU-project GrapeGen06" (8th - 10th July, 2008), while the 'Italian Vitis Database' and the 'Vitis Database Working Group' have been officially presented during the second Italian national symposium of viticulture (Marsala, Sicily, 14-19 July 2008. The public level of the 'Italian Vitis Database' (www.vitisdb.it) has been opened during the third Italian national symposium of viticulture (S.Michele all' Adige, Trento, 5-9 July 2010)..

\section{MATERIALS AND METHODS}

The logical and conceptual scheme of the application for a universal vitis database was mainly prepared in 2004 by Dr. D'Onofrio as his thesis of the master of bioinformatics of University of Turin, while the physical implementation has started in 2007 and it is still in progress.

The logical and conceptual scheme, and consequently the definition of the static (data) and dynamic (data management) aspects, followed the relational model and it resulted from the analysis of literature and plant databases, and from the specificity of viticulture and of possible requirements of the potential users of the application.

As concern the physical implementation, it has been identified and studied the main functions of the application and consequently it has been chosen the more appropriate informatics technologies. Then, it has been decided the informative aspect of the web site and the relationships of the different levels with the intend to obtain an homogeneous, well structured and easily navigable system. Thereafter, the structure and colours of the web site pages and the main masks for the management, visualization and refreshment of data have been designed in conformity to logical and conceptual scheme. Subsequently, the masks of management of all classes of data, of general utility and administration have been created

\section{RESULTS AND DISCUSSION}

The application for the 'Universal Grapevine Database' allows a decentralized data management: the registered users have the possibility to submit and to manage his own data at any time. 


\section{Level of visualization}

In this database the data have three different levels of visualisation: private level, middle level and public level. The registered user (submitter) has the access to his private level and to middle level.

1. Private level. The data in the private level are visible only to his submitter. This level represents a powerful tool for the description, characterization and management of grapevine accession. All the private data can be compared with the data in the middle level. The submitter can elevate to middle level each single accession with all the data associated.

2. Middle level. The data in the middle level are visible to all other submitters. The middle level allows to share the data among all the submitter of the database and consequently it allows the identification of synonyms and homonyms, of duplications and errors before the elevation of the data in the public level.

3. Public level. The data in the public level are visible to all public users. The elevation of data from private or middle level to public level is requested by his submitter and must be approved by a specific Scientific Committee. So, while the private and middle levels represent a useful tool for the characterization of grapevine varieties and accessions, the data of the public level represents a reference for all the whole scientific community and all public users.

\section{Users}

The application has three types of users: public users, registered users (submitters), and the administrator.

1. Public users. All the generic people. They can navigate in the public level of the database without authentication.

2. Submitters. The submitters are registered users that with a specific username and password can have the access to the private and middle levels.

3. Administrators. Responsible for database's functionality. The administrator is also responsible for the management and modification of the application's structure upon suggestion of the Scientific Committee.

\section{Scientific Committee}

The Scientific Committee has the responsibility to approve the data for the public level, to approve the registration of new submitters, to make decisions about the management of the database and about the modification of the software's structure. Actually the Scientific Committee is composed by the database administrator, member of Department of Fruit Science and Plant Protection (University of Pisa) that promoted the project, expert in viticulture, expert in ampelography, expert in molecular biology, expert in analysis of grape secondary metabolites.

\section{Classes of data}

The main classes of data in the database are: 'grapevine variety', 'grapevine accession', 'microsatellite profile', 'ampelographic-ampelometric and phenologicalproductive descriptors', berry polyphenols and aroma profiles (Fig. 2).

1. Variety. In the 'variety' main page (Fig. 3) some general information are reported: botanical information, official and documented synonyms, wrong 
denominations, released clones, a short history of the variety and information on distribution and variation, agronomical characteristics, technological use and bibliography. The general information of a variety are managed by a single submitter (reported on the variety's page) with the permission of the Scientific Committee. In the variety's page are also showed the microsatellite profile, ampelographic-ampelometric descriptors and the photos of the 'variety main accession'. The 'variety main accession' must be approved by the Scientific Committee, and it is an accession that has at least the minimum microsatellite profile, the minimum ampelographic descriptors and a photo of shoot, adult leaf and bunch. The page of a variety can appear in the public level only if the main accession has been approved for public level. A variety groups all the accessions having a microsatellite profile compatible with that one of the 'variety main accession'.

2. Accession. The upload of an accession in the database needs at least the minimum microsatellite profile. The other classes of accession's data are: ampelographicampelometric descriptors, phenological-productive descriptors, berry polyphenols, berry aroma, berry sensorial profile, sanitary status, true-to-type information, photos of all the main ampelographic organs and bibliography.

3. Microsatellite profile. The microsatellite profile of an accession can include all the possible characterized microsatellite loci. Actually the minimum microsatellite profile includes the 6 loci suggested in the EU-project GENRES CT96 No 81 and it will be extended to the 9 loci identified in the current European GrapeGen06 project. The application allows a specific standardization's procedure of microsatellite profile based on some specific selected accessions called 'system accessions' and on the submitter microsatellite profile of reference (submitter microsatellite profile). Both no-standardized data and standardized microsatellite data are maintained in the database (the nostandardized data are visible only in the middle and private levels). Only the accessions with standardized microsatellite profile can be elevated to the middle and public levels.

4. Morphological, phenological and productive descriptors. In the database it is possible to upload all the ampelographic, ampelometric, phenological and productive descriptors as reported in the second edition of the OIV descriptor list for grape varieties and Vitis species (OIV, 2009). For the variety's main accessions there is a minimum list of OIV ampelographic descriptors.

5. Berry profiles. Berry polyphenol, aroma and sensorial profiles include all the main parameters reported in the literature, separately for skin, pulp and seed. The system automatically calculates some specific ratios among polyphenols and aroma that are useful for the variety characterization as reported in the literature.

6. Sanitary status. In the sanitary status section are reported the established information decided at international and national level.

7. True-to-type. About the true-to-type, for each accession the information as suggested by Schneider Anna.are reported

\section{Photos.}

The photos of all the main ampelographic organs can be introduced in the database: shoot, bud, leaf, petiol sinus, flower, berry, seed and bunch.

\section{Language}

The application can support all the possible languages and the language can be changed at any time during the navigation. Actually the English and Italian language have been implemented. 


\section{Search options}

Several search options have been implemented: by general parameters, by ampelographic and ampelometric descriptors, by microsatellite profile.

The search by microsatellites is possible by ranges, by a three steps standardization procedure (Fig. 4), that calculate the similarity index and the cumulative similarity index and also indicate the possibility of direct parentage. Moreover, the graphical representation of results indicates by colours the similarity of each locus compared among the query and the subject: red, both alleles equals; yellow, one allele equal; blue, different alleles; gray, locus non compared. In the public level the search by microsatellite is performed on varieties' microsatellite profile of reference (microsatellite profile of the variety main accession), while in the middle and private level the research is performed both in standardized and non-standardized microsatellite profile of each accession.

\section{Agreement and registration}

For uploading data in the database or just for the access to the middle level it is necessary to be a registered member. For registration it is necessary to sign a specific agreement. The registered users also became members of the 'Vitis Database Working Group' and consequently can take part in the management and improvement of the application.

\section{CONCLUSIONS}

The application has been implemented using the most recent database software and languages, so it is flexible and dynamic especially as concern the addition of other classes of data, like new type of descriptors and molecular markers. Actually the application is adopted for the 'Italian Vitis Database' but it could be adopted for all other national databases and eventually for a 'Universal Grapevine Database'.

\section{ACKNOWLEDGEMENTS}

Research supported by University of Pisa, ColleMassari s.p.a. and Fondazione socio-culturale Montecucco funds.

\section{Literature Cited}

D’Onofrio, C. 2004. Un database per il profilo microsatellite delle accessioni viticole toscane. Tesi Master Universitario in Bioinformatica, Università di Torino.

D'Onofrio, C. and Scalabrelli, G. 2010. Un database viticolo universale. $2^{\circ}$ Convegno Nazionale di Viticoltura, Marsala 14-19 Luglio 2008. Italus Hortus 17: 328-333

D'Onofrio, C. and Scalabrelli, G. 2009. Un database viticolo Italiano. Enoforum 2009, Piacenza Expo 21-23 Aprile 2009. Abstract n. 9, p. 72

Eu-Project Genres 081, 1997. "Primary description list for grapevine cultivars and species (Vitis L.)", Institut für Rebenzüchtung Geilweilerhof, Siebeldingen, Germany, 1997. OIV, 2009. OIV descriptors list for grape varieties and Vitis species ( $2^{\text {nd }}$ edition), Paris 


\section{Figures}

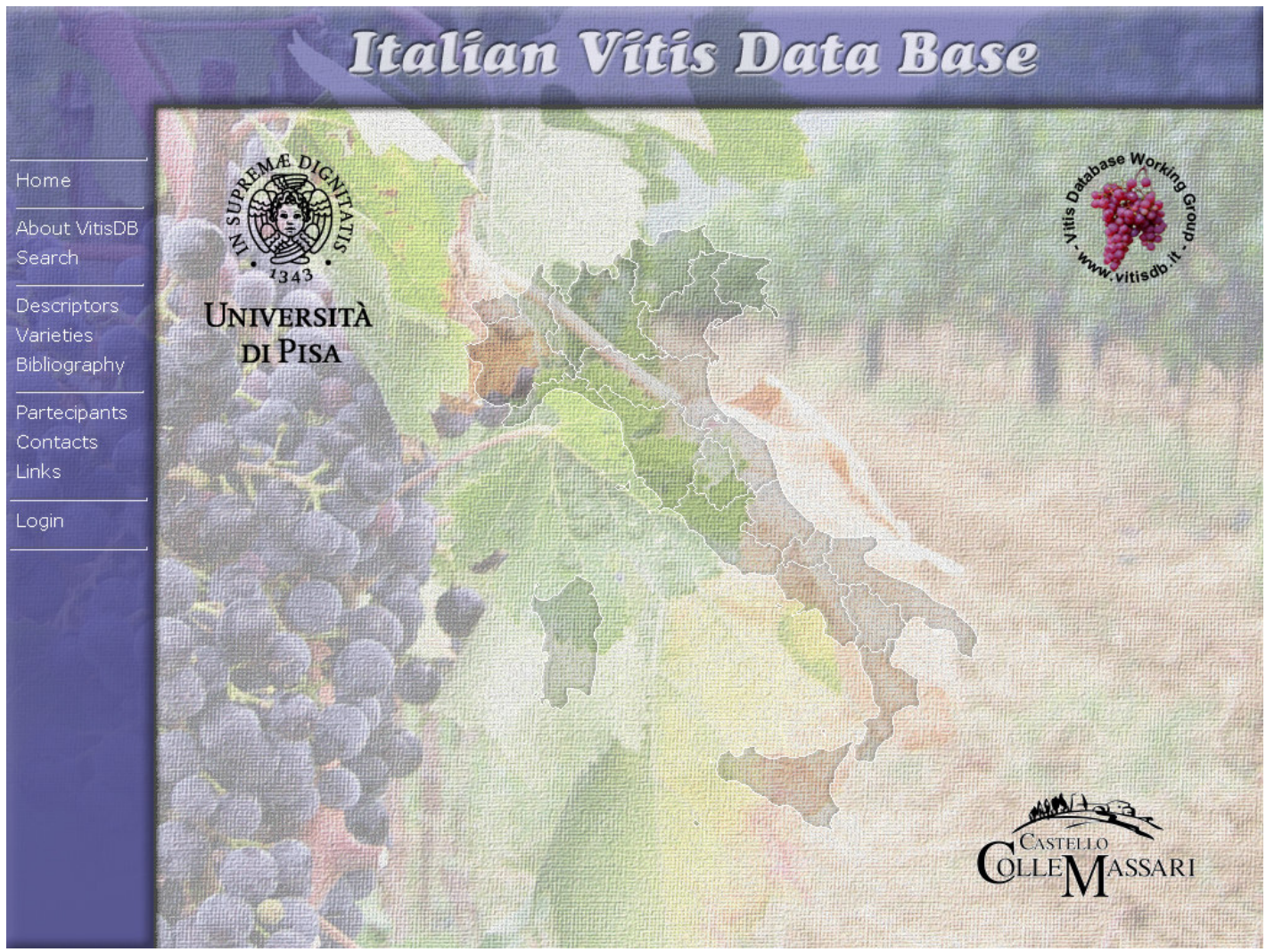

Fig. 1. Home page of the 'Italian Vitis Database' (www.vitisdb.it) managed by the 'Vitis Database Working Group'.

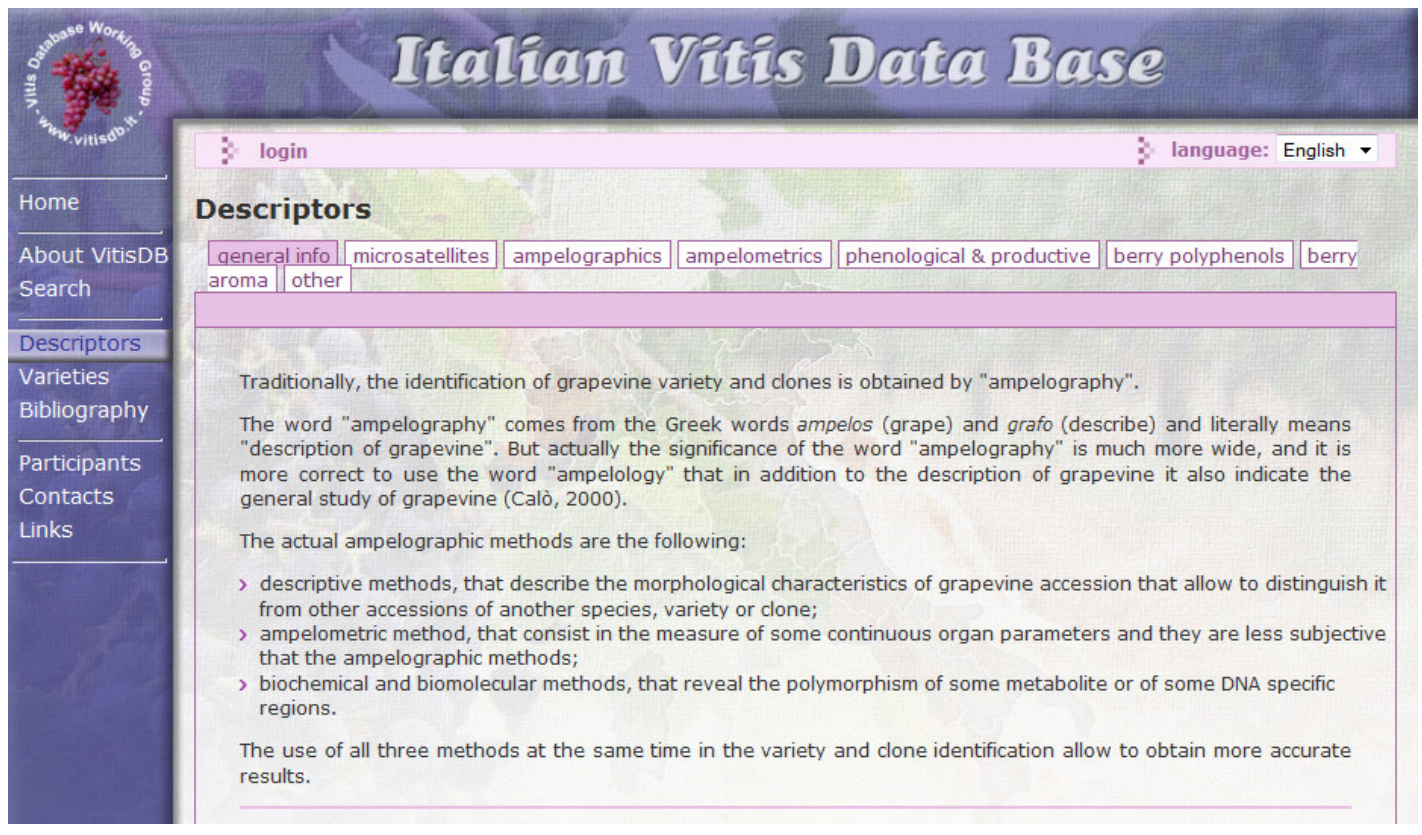

Fig. 2. Descriptors' page. 


\section{Itatiann Virtis Dation Base}

9 donofrio $\geqslant$ logout

8 language: English -

Home

Variety Sangiovese (vitisdb-var_1)

out Vitis DB

Search

$\sqrt{\text { view edit }}$

general info microsatelite profile ampelography ampelometry accessions

general information managed by

Dipartimento di Coltivazione e Difesa delle Specie Legnose "G Scaramuzzi" - Università di Pisa

\section{Participants}

Contacts

Links

botanical information

name: Sangiovese

specie: Vitis vinifera

parent 1: Ciliegiolo

variety group: not available

subspecie: sativa

parent 2: Calabrese di montenuovo

variety for: wine

\section{synonyms (23)}

> "Sangioveto" ()

documented synonyms (18)

"Morellino" (Scansano, IT), "Nielluccio" (Corse, FR), "Prugnolo" (), "Prugnolo gentile" (), "Sangiogheto" (),

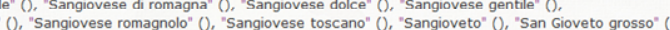

Sangioveto montanino" (), "Sanzoveto" (), "San zoveto" (), "Uvetta" ()

wrong denominations ( 5 )

> "Ciliegiolo" (), "Montepulciano" (), "Moscato nero" (), "Moscato rosso" (), "Uva Tosca" ()

\section{released clones (87)}

"T - 9 ISV - CSV", "1 - Agri 3", "T - Agri 45", "T - AGRI 6", "1 - Ampelos TEA 100", "1 - Ampelos TEA 15"

1- Ampelos TEA 7", "I - Ampelos TEA 8", "T - Ampelos TEA 9", "T - AP-SG 1", "I - AP-SG 2", "I - B-BS-11", "T - BF 10",

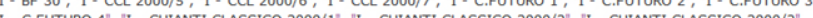

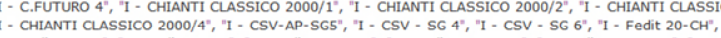

" Fedit 21-CH", "T - Fedit 22-CH", "T - Fedit 2 ESAVE", "I - Fedit 30 ESAVE", "T - Fedit 38 ESAVE", "T - ISV 2",

- ISV RC 1", "T - JANUS-10", "T - JANUS-20", "T - JANUS 50", "T - MI-BF-50", "T - MI-TIN-20", "I - MI-TIN-30",

- MI-TIN-40", "I - Montalcino 42", "I - Peccioli 1", "I - Rauscedo 10 (Grosso Lamole)",

- Rauscedo 24 (Medio Predappio), 'T-SA - PA - 9", T-SG 12 T, "T-SG 2 T, 'T - SG 4 T", T- SG-CDO-4",

- SG-CDO-6", "I - SG-P.A-1", "1 - SG-P.A-8", "I - SS-F9-A5-48", "T - TEA 6", "I - TIN-10", "I - TIN-50",

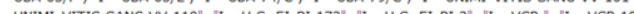

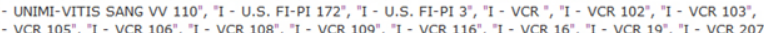

- VCR 209", "I - VCR 214", "I - VCR 218", "I - VCR 23", "I - VCR 237", "I - VCR 30", "I - VCR 4", "I - VCR 5",

- VCR 6
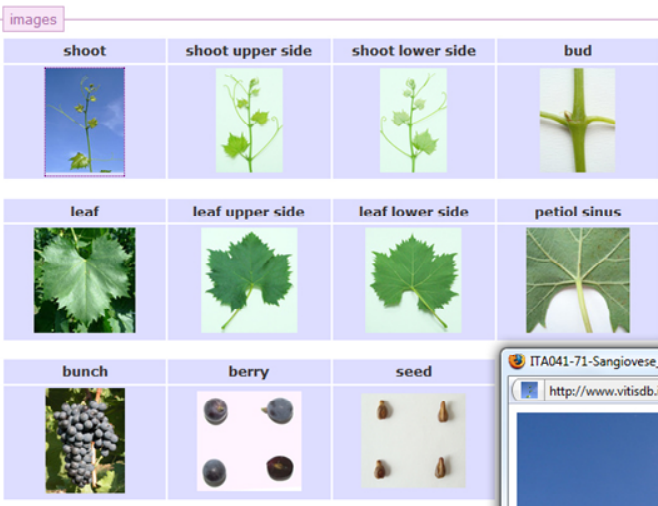

short history

The lack of historical evidence before the sixteenth century makes it explains the great interest to find out the ongin of its name. The name over which "Toscana" and "Emilia Romagna" have been quarrelling for $m$

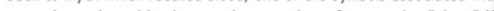
Jove- (sanguis Jovis). The name's semantics refers to yoke, "giogo" (ju gio'vese, that is bor Other connections among the Etruscan language, the religious aspects hypothesized. In a phrase not completely interpreted written in an Etru calendar used to wrap an Egyptian mummy of the first century AD, the someone who does a rite), thezin-eis (offer to the God) or sani-sva, ve Sangiovese that has the meaning of father or ancestor standing for 2001).

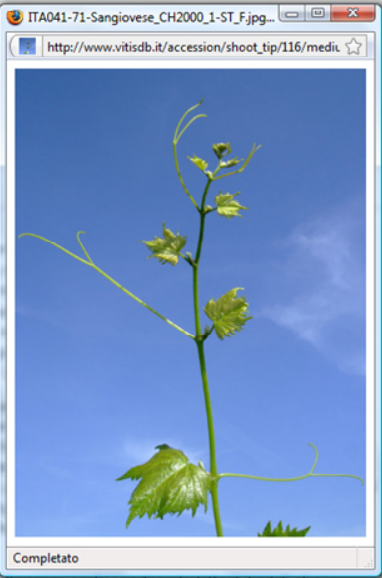

Fig. 3. Variety's page. 


\section{Ifalian Vifís Dafta Base}

Home

About VitisDB

Search

Descriptors

Varieties

Bibliography

Participants

Contacts

Links

$\longrightarrow$

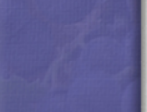

8 login

Variety search by standardized microsatellite profile

generic by microsatellite profile by standardized microsatelite profile

Step 3 - risultati della ricerca effettuata

Variety selected for comparision Sangiovese

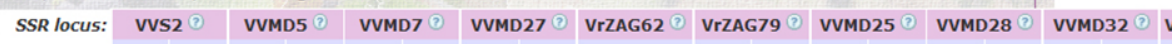

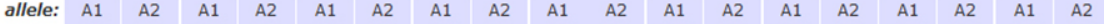

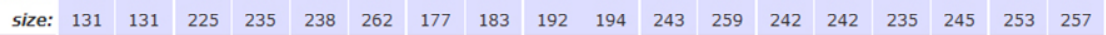

Your SSR

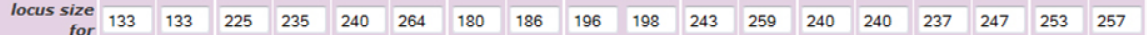

Sangiovese:

deviation of

allele

lengths in
base pairs

brofile of the

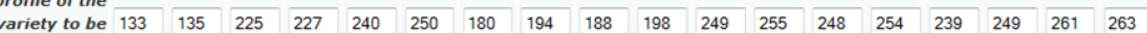

identified:

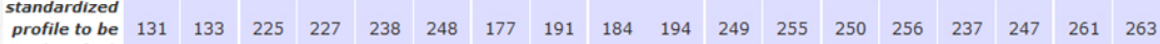

identified:

Error range 2

$(+/-)(2) 2$

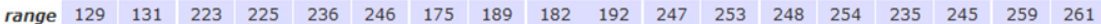

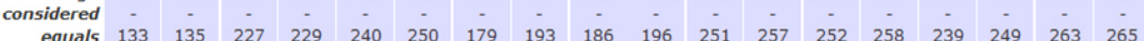

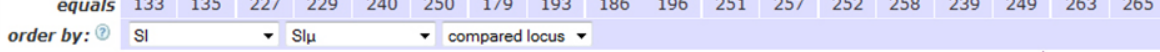

\begin{tabular}{|lll|l|l|l|l|}
\hline similarity graph & search \\
\hline & both alleles equals one allele equal different alleles not compared \\
\hline
\end{tabular}

\begin{tabular}{|c|c|c|c|c|c|c|c|c|c|c|c|c|c|c|c|}
\hline SSR locus: & vvs2 & vVMDS & VVMD7 & VVMM27 & VrZAG62 & VrZAG79 & 9 VVMD25 & 5 VVMD28 & 3|VVMD32 & SI & $\operatorname{SI} \mu$ & $\begin{array}{c}\text { compared } \\
\text { locus }\end{array}$ & $\begin{array}{l}\text { equals } \\
\text { allels }\end{array}$ & s. $\begin{array}{c}\text { may } \\
\text { be } \\
\text { parent }\end{array}$ & \\
\hline Aleatico & & & & & & & & & & 1.0 & 9.0 & 9 & 18 & true & details \\
\hline Teroldeqo & & & & & & & & & & 0.5 & 4.5 & 9 & 9 & false & details \\
\hline Famoso & & & & & & & & & & 0.5 & 4.0 & 8 & 8 & false & details \\
\hline Sanqiovese & & & & & & & & & & 0.4444 & 44.0 & 9 & 8 & false & details \\
\hline Vermentino & & & & & & & & & & 0.3889 & $\begin{array}{l}93.5 \\
\end{array}$ & 9 & 7 & false & details \\
\hline Grianolino & & & & & & & & & & 0.4167 & 2.5 & 6 & 5 & false & details \\
\hline Ruqqine & & & & & & & & & & 0.4167 & $\begin{array}{ll}7.5 \\
\end{array}$ & 6 & 5 & false & details \\
\hline Arneis & & & & & & & & & & 0.3333 & \begin{tabular}{|l|l|}
3 & 2.0 \\
\end{tabular} & 6 & 4 & false & details \\
\hline
\end{tabular}

Search Results

Aleatico

SSR locus: VVS2 VVMD5 VVMD7 VVMD27 VrZAG62 VrZAG79 VVMD25 VVMD28 VVMD32

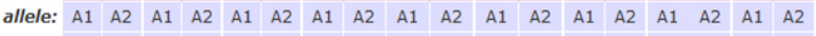
query 1 \begin{tabular}{lllllll|l|l|l|l|l|l|l|l|lll|l}
131 & 133 & 225 & 227 & 238 & 248 & 177 & 191 & 184 & 194 & 249 & 255 & 250 & 256 & 237 & 247 & 261 & 263
\end{tabular}

\begin{tabular}{l|l|l|l|l|l|l|l|l|l|l|l|l|l|l|l|l|l|}
131 & 133 & 225 & 227 & 238 & 248 & 177 & 191 & 184 & 194 & 249 & 255 & 250 & 256 & 237 & 247 & 261 & 263 \\
\hline
\end{tabular}

$\underline{\text { Teroldego }}$

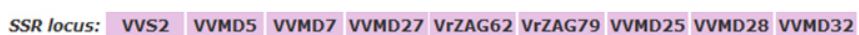

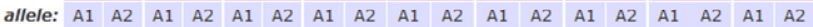

\begin{tabular}{ll|l|l|l|l|l|l|l|l|l|l|l|l|l|l|l|l|l} 
query & 131 & 133 & 225 & 227 & 238 & 248 & 177 & 191 & 184 & 194 & 249 & 255 & 250 & 256 & 237 & 247 & 261 & 263
\end{tabular}

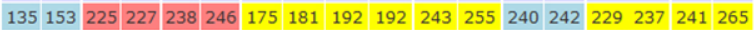

Famoso

\begin{tabular}{l|l|l|l|l|l|l|l} 
SSR locus: & VVS2 & VVMDS & VVMD7 & VVMD27 & VrZAG62 & VrZAG79 & VVMD25 VVMD28 \\
VVMD32
\end{tabular} allele: A1 A2 A1 A2 A1 A2 A1 A2 A1 A2 A1 A2 A1 A2 A1 A2 A1 A2 \begin{tabular}{l|l|l|l|l|l|l|l|l|l|l|l|l|l|l|l|l|l|l|} 
query & 131 & 133 & 225 & 227 & 238 & 248 & 177 & 191 & 184 & 194 & 249 & 255 & 250 & 256 & 237 & 247 & 261 & 263 \\
\hline
\end{tabular} \begin{tabular}{|l|l|l|l|l|l|l|l|l|l|l|l|l|l|l|l|l}
131 & 131 & 225 & 227 & 238 & 246 & 177 & 187 & 186 & 202 & 241 & 245 & 242 & 242 & 229 & 261
\end{tabular}

Fig. 4. Search by standardized microsatellite profile. 